\title{
Psychophysiological Correlates of Peritraumatic Dissociative Responses in Survivors of Life-Threatening Cardiac Events
}

\author{
Karl-Heinz Ladwiga, b Birgitt Marten-Mittaga Isabel Deisenhoferc \\ Birgit Hofmann $^{a}$ J ohannes Schapperera Sonja Weyerbrock ${ }^{c}$ \\ Natalia Erazo ${ }^{a}$ Claus Schmittc \\ aInstitut und Poliklinik für Psychosomatische Medizin, Medizinische Psychologie und Psychotherapie, \\ Klinikum Rechts der Isar, Technische Universität München, bForschungszentrum für Umwelt und Gesundheit (GSF), \\ Institut für Epidemiologie, Neuherberg, und 'Deutsches Herzzentrum München, Klinik an der Technischen \\ Universität München, Germany
}

\section{Key Words}

Peritraumatic dissociation - Startle experience .

Post-traumatic stress disorder · Cardiovascular disease

\begin{abstract}
The psychophysiological startle response pattern associated with peritraumatic dissociation (DISS) was studied in 103 survivors of a life-threatening cardiac event (mean age 61.0 years, SD 13.95). Mean time period since the cardiac event was 37 (79 IQD) months. All patients underwent a psychodiagnostic evaluation (including the Peritraumatic Dissociative Experiences Questionnaire) and a psychophysiological startle experience which comprised the delivery of 15 acoustic startle trials. Magnitude and habituation to trials were measured by means of electromyogram (EMG) and skin conductance responses (SCR). Thirty-two (31\%) subjects were indexed as patients with a clinically significant level of DISS symptoms. High-level DISS was associated with a higher magnitude of SCR (ANOVA for repeated measures $p=0.017$ ) and EMG ( $p=$ 0.055 ) and an impaired habituation (SCR slope $p=0.064$; EMG slope $p=0.005$ ) in comparison to subjects with no or low DISS. In a subgroup analysis, high-level DISS
\end{abstract}

patients with severe post-traumatic stress disorder (PTSD; $n=11$ ) in comparison to high-level DISS patients without subsequent PTSD $(n=19)$ exhibited higher EMG amplitudes during all trials (repeated measures analysis of variance $F=5.511, p=0.026$ ). The results demonstrate exaggerated startle responses in SCR and EMG measures - an abnormal defensive response to high-intensity stimuli which indicates a steady state of increased arousal. DISS patients without PTSD exhibited balanced autonomic responses to the startle trials. DISS may, therefore, unfold malignant properties only in combination with persistent physiological hyperarousability.

Copyright $\odot 2002$ S. Karger AG, Basel

\section{Introduction}

In the face of an extremely threatening event, subjects may experience immediate dissociative responses, including feelings of detachment, derealization, depersonalization, and out-of-body experiences [1]. Dissociation serves the purpose of temporarily disconnecting the person's experience from his or her feelings [2]. Pertitraumatic dissociation (DISS) can be viewed as a partially adaptive

\begin{tabular}{ll}
\hline KARGER & ( ) 2002 S. Karger AG, Basel \\
Fax +4161306 1234 & 0254-4962/02/0354-0241\$18.50/0 \\
$\begin{array}{l}\text { E-Mail karger@karger.ch } \\
\text { www.karger.com }\end{array}$ & $\begin{array}{l}\text { Accessible online at: } \\
\text { www.karger.com/journals/psp }\end{array}$
\end{tabular}

K.H. Ladwig, PhD, MD habil., Institut und Poliklinik für Psychosomatische Medizin Psychotherapie und Medizinische Psychologie

Universitätsklinikum Rechts der Isar der TUM

Langerstrasse 3, D-81675 München (Germany)

E-Mail kh.ladwig@lrz.tu-muenchen.de 
response to a trauma [3]. In this view, victims of a psychotraumatic event may protect themselves against the overwhelming exposure of threatening stimuli by inhibiting information processing [4].

Empirical evidence, however, suggests that DISS is a risk factor for the development of a subsequent post-traumatic stress disorder (PTSD). In a retrospective approach, studies in Cambodian refugees [5], in Vietnam veterans [6, 7], in firestorm [3] and earthquake [8] survivors, and in traumatized police officers [2] uniformely demonstrated that patients with PTSD exhibited significantly more within-trauma dissociative symptoms than patients without PTSD. In a longitudinal approach, Shalev et al. [9] and more recently Ursano et al. [10] demonstrated that DISS was strongly associated with subsequent development of PTSD.

To date, the mechanisms that link within-trauma dissociation with the development of later PTSD remain largely unidentified. Janet [11] was the first to conceptualize dissociation in the context of physiological hyperarousal. Dissociation, in this sense, may be an expression of greater vulnerability and increased responsiveness of exposure to a threatening event [7]. However, preliminary empirical evaluation of physiological arousal has not confirmed this concept. Griffin et al. [12] studied female rape victims and revealed a suppression rather than an aggravation of autonomic physiological responses upon imaginary exposure to the psychotrauma in the high-dissociation group.

Exaggerated startle responses have been demonstrated to be a criterion for persistent presence of increased arousal in subjects in the aftermath of psychotraumatic events [12-16]. To further elucidate the deteriorating impact of within-trauma dissociation with the development of subsequent PTSD, we employed the startle paradigm to assess an objective measurement of nonspecific hyperreactivity in relation to dissociation. We studied patients who had survived a cardiac arrest. Cardiac arrest survivors and survivors of an acute myocardial infarction (AMI) have experienced a life-threatening situation and, therefore, are at risk to develop PTSD [17, 18]. We expected larger magnitude responses and slower habituation of acoustic startle-induced autonomic parameters [orbicularis occuli electromyogram (EMG) and electrodermal activity] in patients who had experienced DISS.

DISS may be a strong predictor for subsequent PTSD; however, not all patients with symptoms of dissociation during a traumatic event may develop the disease condition. We studied whether this subgroup exhibited a particular psychophysiological response pattern.

\section{Patients and Methods}

\section{Patient Characteristics}

Patients were drawn consecutively from the LICAD (Living with an Implantable Cardioverter Defibrillator) Study initially including 149 patients treated with an automatic implantable cardioverter defibrillator (ICD) who attended the cardiology outpatient clinic of the 'Deutsches Herz Zentrum München' for routine ICD checkup. Patients were not included when the first implantation of an ICD device was less than 3 months ago. Written informed consent was obtained from all patients. Of these patients, 115 had experienced a cardiac arrest or a myocardial infarction and thus fulfilled the inclusion criteria of the present study. Among these, no patient refused to participate. Five patients were excluded from the analysis because of severe hearing loss and 7 patients because of missing data in the psychophysiologic assessment. Thus, the final study population comprised 103 patients. Mean age of these patients was 61.0 years (SD: 13.9), $91(88 \%)$ were male and $12(12 \%)$ were female. Illness onset was sudden cardiac arrest with subsequent reanimation in $71(69 \%)$ patients and AMI in $32(31 \%)$ cases. Mean time period since the acute cardiac event was 37 (79 IQD) months.

We identified 6 patients with PTSD in the study group. For validation of the criterion, we used a diagnostic checklist recommended by the WHO [19] of all symptoms necessary for the current operational ICD-10 diagnosis of PTSD and then counted the prevalence for all study patients. There were also 8 patients who were indexed as partial PTSD patients. Partial PTSD was diagnosed if a minimum number of symptoms for the re-experiencing criterion, and either the avoidance criterion or the hyperarousal criterion were met [20,21].

\section{Acoustic Startle Reflex (ASR) Paradigm}

We adopted the ASR paradigm from Shalev et al. [16]. It comprised 15 loud tones as independent variables (stimuli). The acoustic startle stimulus was a $500-\mathrm{ms}$ burst of $1,000 \mathrm{~Hz}$ with a near instantaneous rise time presented binaurally through headphones (Panasonic). The intensity of the acoustic stimulus was $95 \mathrm{~dB}$ (sound pressure level). Intertrial intervals were randomly selected and ranged from 17 to $32 \mathrm{~s}$.

Dependent variables of the ASR paradigm were the EMG response to assess sensimotor responses and the skin conductance response (SCR) to assess autonomic reactivity.

Signals were amplified and filtered by a bioamplifier (B-scope ${ }^{\circledR}$, Regensburg, Germany). The EMG signal was recorded through 4$\mathrm{mm}$ (sensor diameter) surface electrodes (Biopac Beckman type $\mathrm{Ag} /$ $\mathrm{AgCI}$ ) and filtered in order to obtain a $90-$ to $500-\mathrm{Hz}$ frequency range. SCR was measured directly by a coupler using a constant $0.5 \mathrm{~V}$ through 9-mm (sensor diameter) electrodes (Beckman-type Ag/AgCI) placed on the subject's nondominant palm. SCR was analyzed in a spectrum from $15.9 \mathrm{mHz}$ to $10 \mathrm{~Hz}$ and digitalized at $50 \mathrm{~Hz}$. SCR values were measured in microsiemens. Sampling frequency was $1,000 \mathrm{~Hz}$ for the EMG and $50 \mathrm{~Hz}$ for the SCR.

To assess the magnitude of the startle responses, an EMG score for each tone trial was calculated by subtracting the mean EMG level during the $2 \mathrm{~s}$ immediately preceding tone onset from the highest EMG response measured within $40-200 \mathrm{~ms}$ after tone onset. The response window for skin conductance was 1-4 s after tone onset. Square root transformations were performed on the EMG and SCR scores. 
Table 1. Sociodemographic and clinical characteristics of the study population, stratified for three levels of DISS

\begin{tabular}{|c|c|c|c|c|}
\hline & $\begin{array}{l}\text { No } \\
\text { DISS } \\
(n=31)\end{array}$ & $\begin{array}{l}\text { Low-level } \\
\text { DISS } \\
(\mathrm{n}=40)\end{array}$ & $\begin{array}{l}\text { High-level } \\
\text { DISS } \\
(\mathrm{n}=32)\end{array}$ & $\mathrm{p}$ value \\
\hline Means age (SD), years & $63.9(10.1)$ & $64.5(12.9)$ & $53.9(15.8)$ & $\begin{array}{l}0.002 \\
(\mathrm{~F} \text { test })\end{array}$ \\
\hline \multicolumn{5}{|l|}{ Patients } \\
\hline $\begin{array}{l}\text { Male } \\
\text { Female }\end{array}$ & $\begin{array}{r}27(87 \%) \\
4(13 \%)\end{array}$ & $\begin{array}{c}37(93 \%) \\
3(7 \%)\end{array}$ & $\begin{array}{r}27(84 \%) \\
5(16 \%)\end{array}$ & 0.547 \\
\hline $\begin{array}{l}\text { Education } \\
<\text { High school } \\
\text { High school } \\
\text { University degree }\end{array}$ & $\begin{array}{r}19(61 \%) \\
4(13 \%) \\
8(26 \%)\end{array}$ & $\begin{array}{r}23(58 \%) \\
5(13 \%) \\
12(30 \%)\end{array}$ & $\begin{array}{l}10(32 \%) \\
11(36 \%) \\
10(32 \%)\end{array}$ & 0.060 \\
\hline $\begin{array}{l}\text { Myocardial infarction } \\
\text { Cardiac arrest }\end{array}$ & $\begin{array}{l}12(39 \%) \\
19(61 \%)\end{array}$ & $\begin{array}{l}16(40 \%) \\
24(60 \%)\end{array}$ & $\begin{array}{r}4(12 \%) \\
28(88 \%)\end{array}$ & 0.024 \\
\hline
\end{tabular}

$\chi^{2}$ test, except for age.
Habituation was defined in two ways: (1) as response slope of the regression equation $\mathrm{Y}=\mathrm{bX}+\mathrm{a}$ for trial $2-15$, where $\mathrm{Y}$ equals the magnitude of the response and $\mathrm{X}$ the $\log$ trial number calculated for each subject. (2) As trials-to-nonresponse. An SCR $\leq 0.15 \mu \mathrm{S}$ (untransformed) or an EMG $\leq 18 \mu \mathrm{V}$ (untransformed) was considered as non-response trial. Two consecutive non-response trials fulfilled the non-response criterion.

The room temperature and humidity were maintained at $22^{\circ} \mathrm{C}$ and $55 \%$, respectively. The patient investigation was carried out between $9.00 \mathrm{a} . \mathrm{m}$. and $1.00 \mathrm{p} . \mathrm{m}$. Study subjects underwent a hearing test and received instructions while the electrodes were attached according to published recommendations.

\section{Psychometric Measurements}

A rater-administered version of the Peritraumatic Dissociative Experiences Questionnaire (PDEQ) [22] was used to assess withintrauma dissociation. Because of the retrospective design of the study, patients were asked whether a symptom had been present at the time of the trauma without rating the severity of the symptom. Thus, the range of the scale with eight items was from 0 to 8 . The internal consistency (Cronbach's $\alpha$ ) was 0.68 . To assess the extent of retrograde amnesia, patients were asked whether they could remember details immediately at onset, some hours before, or whether they suffered from a patchy recall loss of 1 or more days before the event.

The Impact of Event Scale (revised version) IES-R [23-25] is a 22-item self-report inventory that indexes intrusive and avoidance symptoms (each subscale with 8 items, range 1-4) and startle symptoms (6 items, range 1-4). Furthermore, patients were asked whether the event had markedly changed their lives and whether they could actually recall the event. Prior traumatization was assessed by presenting a list of possible traumatizing events

\section{Statistics}

Group differences in continuous and categorical data were examined by $t$ test, Mann-Whitney test, Kruskal-Wallis test and $\chi^{2}$ test, respectively $(\alpha \leq 0.05)$. Group differences for the 15 startle trials were calculated by analysis of variance (ANOVA) for repeated measures. Statistical analysis was carried out with SPSS (version 10.0).

\section{Results}

\section{Characteristics of the Dissociation Groups}

In the immediate aftermath of an acute life-threatening cardiac event, 72 (70\%) of the 103 surviving patients in the present study experienced one or more symptoms of DISS (mean $=1.82$, SD 1.81, range $=0-8$ ). Approximately one third $(n=32)$ of the sample reported three or more symptoms, which was considered as a clinically meaningful level of dissociative responses.

Patients with a high level of DISS (table 1) were significantly younger and more likely to have a higher educational level. There were significantly more patients with a history of a cardiac arrest than with a myocardial infarction in the high DISS group, indicating more intense psychotraumatogenic properties of the cardiac arrest situation.

Table 2 displays the psychotraumatic impact of the event stratified for the three DISS groups. The data confirm a close relationship between the DISS level and the subsequent development of core PTSD symptoms: intrusion, avoidance and startle. High DISS was also associated with a higher prevalence of retrograde amnesia, both for hours $\left(\chi^{2}=15.90, \mathrm{p}<0.001\right)$ and for days $\left(\chi^{2}=9.87\right.$, $\mathrm{p}<0.007)$. It is of interest to note that the time span which 


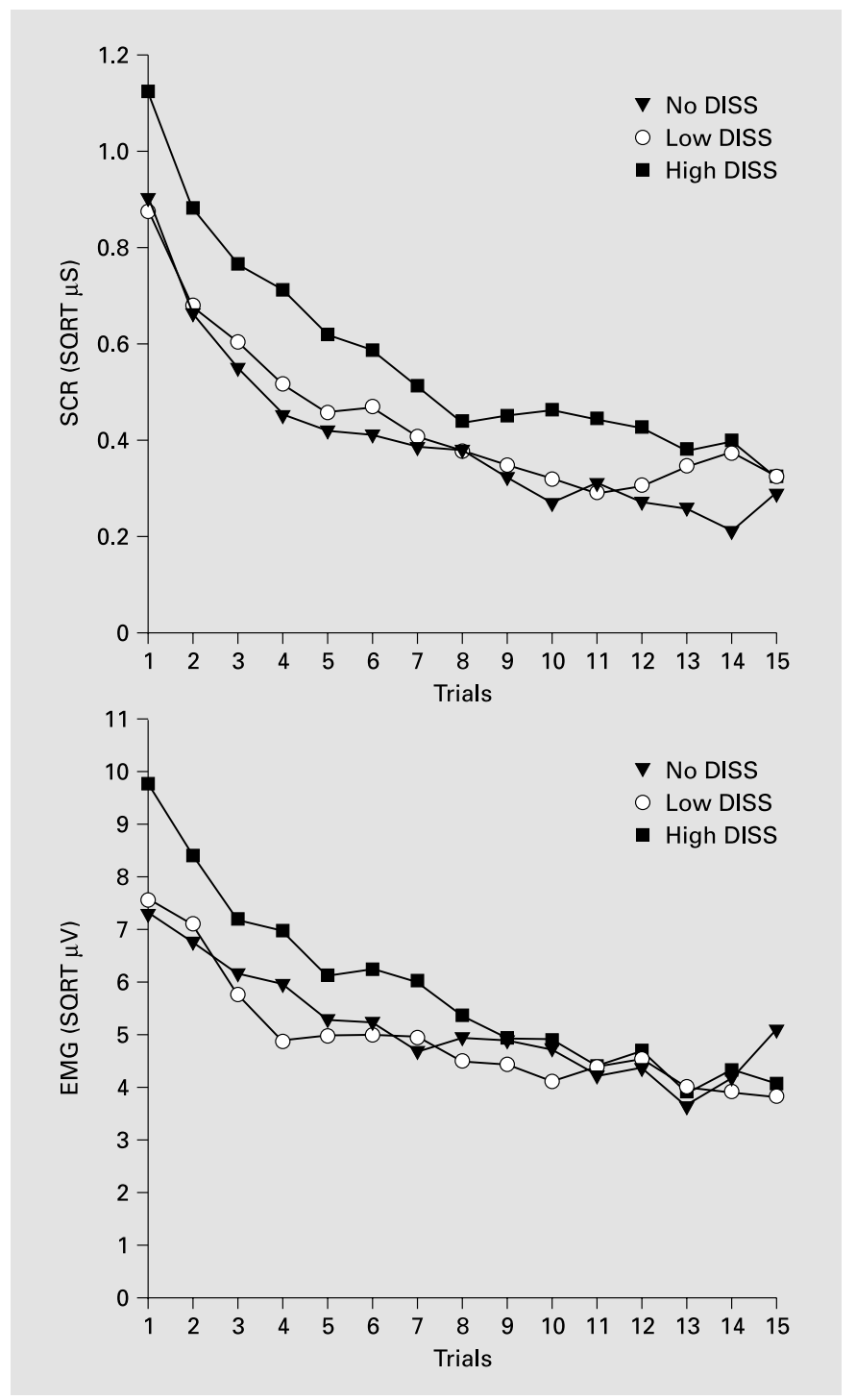

Fig. 1. Response means for SCR (in $\mu \mathrm{S}$ ) and EMG responses (in $\mu \mathrm{V}$ ) for 15 trials, stratified in patients with no, low and high DISS. $\mathrm{SQRT}=$ Square root transformation.

with no or low DISS levels $(n=71)$ for the SCR and EMG both for the mean magnitude of the first trial and for the average over all 15 trials. Table 3 further shows that SCR and EMG habituation was impaired in the high-level DISS group and reached borderline significance for both parameters of habituation (trials to non-response and slope) except for the EMG slope which exhibited a highly significant impaired decrease in responsiveness $(\mathrm{p}=$ 0.005 ) in the high-level DISS group.

Every patient in the full PTSD group suffered from high-level DISS. Accordingly, the positive predictive
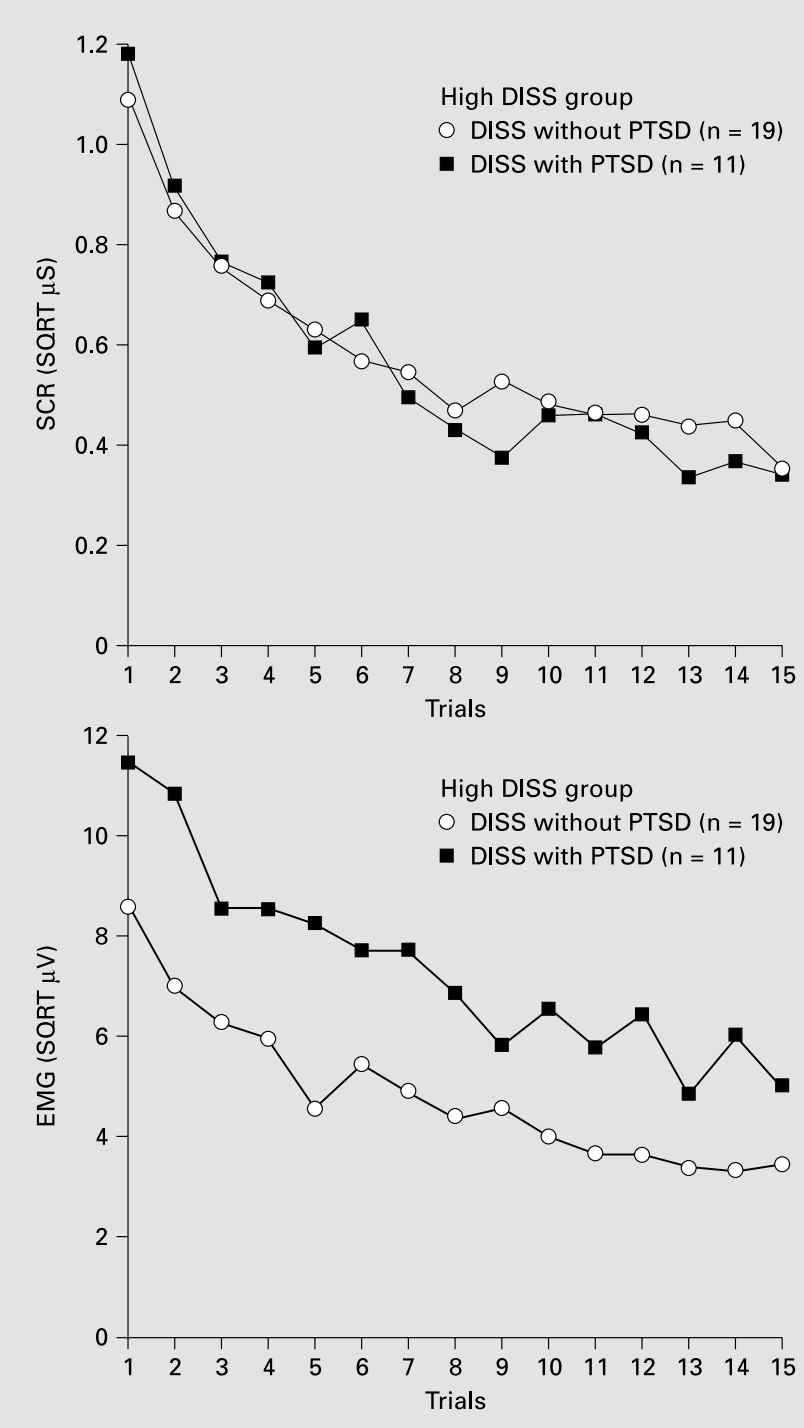

Fig. 2. Response means for SCR (in $\mu \mathrm{S}$ ) and EMG responses (in $\mu \mathrm{V}$ ) for 15 trials in patients with high levels of dissociation, stratified for patients with and without subsequent development of PTSD. SQRT = Square root transformation.

power was $78.6 \%$ and the negative predictive power $76.8 \%$ for high-level DISS to predict subsequent full PTSD. Nevertheless, a considerable subgroup of $19(63 \%)$ patients in the high DISS group did not develop a subsequent PTSD. We further characterized this particular patient subgroup to assess what might have inhibited the development of the psychotraumatic disease process in these patients. The subgroup analysis revealed (fig. 2) that high-level DISS patients with subsequent PTSD $(\mathrm{n}=11)$ in comparison to high-level DISS patients who did not develop PTSD $(n=19)$ exhibited significantly higher 
EMG values $(F=5.511, p=0.026)$ whereas no differences in SCR measurements were observed $(\mathrm{F}=0.185, \mathrm{p}=$ 0.878).

\section{Discussion}

\section{Prevalence of DISS}

The present investigation reveals that the experience of dissociative symptoms is common among patients who survived a life-threatening cardiac event. To our knowledge, this phenomenon has not been investigated in this particular patient group. However, the symptomatology has in part been studied in attempts to investigate neardeath experiences [26] which have an extremely low incidence $(0.3-0.5 \%)$ in cardiac arrest survivors [27]. Interestingly, those vivid hallucinations have been discussed in the context of (hypoxic) stress-induced limbic lobe dysfunction [28].

Seventy percent of the present study population experienced one or more of such symptoms in the immediate aftermath of an acute life-threatening cardiac event. This is similar to the finding of Ursano et al. [10] who reported $79 \%$ of DISS symptoms assessed with the PDEQ in patients 1 month after motor vehicle accidents. The incidence of a clinically meaningful level of DISS (with more than 3 symptoms reported) was $35 \%$ in the motor vehicle accident study [29] and was $31 \%$ in the present study.

Among factors which are associated with DISS, higher levels of DISS were more prevalent in younger patients in the present study. Age was also negatively associated with dissociative tendencies in emergency workers [30], in Vietnam veterans [31], and in motor vehicle accident victims [29].

Dissociation may be a marker of prior traumatization. Shalev et al. [9] have assumed that DISS may result from a defensive behavior acquired during previous traumatization. The data of the present study do no support this assumption. Our results are similar to those of a vehicle accident study [10,29] which also did not find such an association. Fullerton et al. [29] concluded from their findings that the neurobiological mechanisms that relate DISS and subsequent PTSD appear to be different from those associated with kindling due to a prior traumatic event.

\section{Startle Response Patterns}

A more direct approach to neurobiological mechanisms is provided by the assessment of the ARS experiment which systematically measures flexor motor and autonomic nervous system responses to loud and sudden tones. Although the ARS is a stereotyped response it shows considerable plasticity. The present study reveals a significantly exaggerated startle response amplitude for the SCR and a heightened (however not significant) startle response for the EMG in patients who experienced high levels of dissociative symptoms during a life-threatening event. Habituation is markedly impaired in both domains, however, being highly significant in EMG measurements. The data suggest a persistent presence of increased arousability which has been proven for patients in the aftermath of psychotraumatic events [12-16]. The impaired habituation in the index group additionally indicates that these patients remain in a steady state of an increased fight/flight reaction [4, 16, 32]. A failure of extinction of startle responses is characteristic of individuals exposed to extreme stressors [33]. The startle data support the hyperarousal assumption first proposed by Janet [11] in the beginning of the last century.

Modifications in startle responses have been linked to higher central nervous system regions, mainly to the central nucleus of the amygdala which is an important mediator of emotional memory $[33,34]$. This region receives input from the perirhinal cortex and activates directly the nucleus reticularis pontis caudalis [35]. Lesions of the central nucleus of the amygdala block ASR [36], whereas electrical stimulation enhances ASR [37].

There is only one published report in which SCR and EMG responses in DISS patients were studied [12]. Surprisingly, these investigators found lower physiological reactivity during trauma imagery in the high dissociation group which contrasts with previous findings of a higher physiological reactivity in PTSD patients. The investigators concluded from their findings that the result may mask differences in the PTSD group as a whole.

\section{Subgroup Analysis}

The lack of a distinct subgroup of patients with clinically meaningful levels of dissociation in the present study to predict PTSD suggests the need to investigate those mechanisms having impact on the subsequent disease process [38]. The data of the present study reveal that patients with high levels of DISS who later develop PTSD exhibit significantly higher EMG magnitudes and lower habituation than patients with high levels of DISS but without subsequent PTSD development.

The cross-sectional design of the present study does not allow a causal explanation. However, these results point to a non-provoked inherent hyperpotentiation of vulnerable subjects [39] which may suggest a biological 
basis for susceptibility to malignant trauma processing. Individual differences in vulnerability and resilience to dissociation may be present already at the level of neuronal sensitization [40].

Limitations. The most important limitation of this study is its cross-sectional design and the results should be interpreted with caution. However, to the best of our knowledge, psychophysiological startle data have not been analyzed in DISS patients before and thus the present data provide the empirical basis for defining hypotheses which have to be confirmed in a prospective study. The results may be restricted to traumatic events which are of short duration and followed by rapid rescue treatment. The extent to which the findings may be generalized to other PTSD populations remains unclear. In the present study, SCR and EMG data were not always synchronized, similar to previous published studies $[15,16]$. Yet, it remains speculative why synchronicity is often not present for different domains of psychophysiological response.

\section{Conclusion}

Dissociation is a response pattern to overwhelming threat characterized by an immediate breakdown of information processing. Although it may protect the victim from a full conscious appreciation of the threating appraisal at the time of a trauma, it does not protect against subsequent development of PTSD. Patients with dissociate symptoms were at increased risk of subsequent PTSD and also exhibited higher levels of arousal. However, the experience of dissociation symptoms alone may not lead to a malignant disease process. Dissociation may, therefore, induce malignant properties only in combination with persistent physiological hyperarousal triggered by central nervous mechanisms. Longitudinal studies are required to investigate whether exaggerated startle responses (i.e. differences in neuronal sensitization) are already present at an early stage after trauma exposure when patients still do not differ in their clinical appearance and acute symptomatology.

\section{Acknowledgment}

This research project was supported by a research grant from the Medical Faculty of the 'Technische Universität München' (KKF-H 18-97) and by a non-restricted research grant from Guidant Medical devices (both grants to K.-H.L.). We are indebted to Jack Favor (GSF Institute of Human Genetics) for his valuable advice in the preparation of the manuscript.

\section{References}

1 Van der Kolk BA, Pelcovitz D, Roth S, Mandel FS, McFarlane A, Herman JL: Dissociation, somatization, and affect dysregulation: The complexity of adaptation to trauma. Am J Psychiatry 1996;153(suppl):83-92.

2 Carlier IVE, Lamberts RD, Fouwels AJ, Gersons BPR: PTSD in relation to dissociation in traumatized police officers. Am J Psychiatry 1996;153:1325-1328.

3 Koopman C, Classen C, Spiegel D: Predictors of posttraumatic stress symptoms among survivors of the Oakland/Berkeley, Calif., firestorm. Am J Psychiatry 1994;151:888-894.

4 Van der Kolk BA, van der Hart O, Marmar $\mathrm{CR}$ : Dissociation and information processing in posttraumatic stress disorder; in van der Kolk BA, McFarlane AC, Weisaeth L (eds): Traumatic Stress: The Effects of Overwhelming Experience on Mind, Body, and Society. New York, Guilford, 1996, pp 303-327.

5 Carlson EB, Rosser-Hogan R: Trauma experiences, posttraumatic stress, dissociation, and depression in Cambodian refugees. Am J Psychiatry 1991;148:1548-1551.
6 Bremner JD, Southwick S, Brett E, Fontana A, Rosenheck R, Charney DS: Dissociation and posttraumatic stress disorder in Vietnam combat veterans. Am J Psychiatry 1992;149:328332.

7 Marmar CR, Weiss DS, Schlenger WE, Fairbank JA, Jordan BK, Kulka RA, Hough RL: Peritraumatic dissociation and posttraumatic stress in male Vietnam theater veterans. Am J Psychiatry 1994;151:902-907.

8 Cardena E, Spiegel D: Dissociative reactions to the San Francisco Bay Area earthquake of 1989. Am J Psychiatry 1993;150:474-478.

9 Shalev AY, Peri T, Canetti L, Schreiber S: Predictors of PTSD in injured trauma survivors: A prospective study. Am J Psychiatry 1996;153: 219-225.

10 Ursano RJ, Fullerton CS, Epstein RS, Crowley B, Vance K, Kao TC, Baum A: Peritraumatic dissociation and posttraumatic stress disorder following motor vehicle accidents. Am J Psychiatry 1999; 156:1808-1810.

11 Janet P: L'amnésie et al dissociation des souvenirs par l'émotion. J Psychol 1904;4:417-453.
12 Griffin MG, Resick PA, Mechanic MB: Objective assessment of peritraumatic dissociation: Psychophysiological indicators. Am J Psychiatry 1997;157:1081-1088.

13 Pitman RK, Orr SP, Forgue DF, de Jong JB, Claiborn JM: Psychophysiological assessment of posttraumatic stress disorder imagery in Vietnam combat veterans. Arch Gen Psychiatry 1987;47:970-975.

14 Butler RW, Braff DL, Rausch JL, Jenkins MA, Sprock J, Geyer MA: Physiological evidence of exaggerated startle response in a subgroup of Vietnam veterans with combat-related PTSD. Am J Psychiatry 1990;147:1308-1312.

15 Orr SP, Solomon Z, Peri T, Pitman RK, Shalev A: Physiological responses to loud tones in Israeli veterans of the 1973 Yom Kippur War. Biol Psychiatry 1997;41:319-326.

16 Shalev AY, Scott PO, Peri T, Schreiber S, Pitman RK: Physiologic responses to loud tones in Israeli patients with posttraumatic stress disorder. Arch Gen Psychiatry 1992;49:870-875. 
17 Ladwig KH, Dammann G: Psychological adaptation after successful out-of-hospital resuscitation (editorial). J Psychosom Res 1997;43:559_ 564.

18 Ladwig KH, Schoefinius A, Dammann G, Danner R, Gürtler R, Herrmann R: Long acting psychotraumatogenic properties of a cardiac arrest experience. Am J Psychiatry 1999; 156:912-919.

19 Hiller W, Zaudig M, Mombour W: International Diagnostic Checklists for ICD-10 and DSMIV. Seattle, Hogrefe \& Huber, 1996.

20 Schützwohl M, Maercker A: Effects of varying diagnostic criteria for posttraumatic stress disorder are endorsing the concept of partial PTSD. J Trauma Stress 1999;12:155-165.

21 Blanchard EB, Hickling EJ, Vollmer AJ, Loos WR, Buckley TC, Jaccard JJ: Short term follow-up of post-traumatic stress symptoms in motor vehicle accident victims. Behav Res Ther 1995;33:369-377.

22 Marmar CR, Weiss DS, Metzler TI: The Peritraumatic Dissociative Experiences Questionnaire; in Wilson JP, Keane TM (eds): Assessing Psychological Trauma and PTSD: A Handbook for Practitioners. New York, Guilford, 1995.

23 Horowitz MJ, Wilner N, Alvarez W: Impact of Event Scale: A measure of subjective stress. Psychosom Med 1979;41:209-218.

24 Ferring D, Filipp SH: Teststatistische Überprüfung der Impact of Event-Skala: Befunde zu Reliabilität und Stabilität. Diagnostica 1994; 40:344-362.
25 Maercker A, Schützwohl M: Assessing mental effects of traumatic events: The Impact of Event Scale - Revised. Diagnostica 1998;44: 130-141.

26 Greyson B: The near-to-death experience scale. Construction, reliability, and validity. J Nerv Ment Dis 1983;171:369-375.

27 Martens PR: Near-to-death experiences in outof-hospital cardiac arrest survivors. Meaningful phenomena or just fantasy of death? Resuscitation 1994;27:171-175.

28 Carr D: Pathophysiology of the stress inducedlimbic lobe dysfunction: A hypothesis for NDEs. Anabiosis 1982;2:75-89.

29 Fullerton CS, Ursano RJ, Epstein RS, Crowley B, Vance KL, Kao TC, Baum A: Peritraumatic dissociation following motor vehicle accidents. Relationship to prior trauma and prior major depression. J Nerv Ment Dis 2000;188:267272.

30 Marmar CR, Weiss DS, Metzler TJ, Delucchi $\mathrm{K}$ : Characteristics of emergency services personnel related to peritraumatic dissociation during critical incident exposure. Am J Psychiatry 1996;153(suppl):94-102.

31 Zackzick DF, Marmar CR, Weiss DS, Metzler $\mathrm{T}$ : Does trauma linked dissociation vary across ethnic groups. J Nerv Ment Dis 1994;182:576582.

32 Southwick RJ, Krytal JH, Morgan CA, Johnson D, Nagy LM, Nicolaouu A, Henninger GR, Charney DS: Abnormal noradrenergic function in posttraumatic stress symptoms. Arch Gen Psychiatry 1993;50:266-274.
33 Bremner JD, Krystal JH, Charney DS, Southwick SM: Neural mechanisms in dissociative amnesia for childhood abuse: Relevance to the current controversy surrounding the 'false memory syndrome'. Am J Psychiatry 1996; 153(suppl):71-82.

34 Campeau S, Davis M: Involvement of the central nucleus and basolateral complex of the amygdala in fear conditioning measured with fear-potentiated startle in rats trained concurrently with auditory and visual conditioned stimuli. J Neurosci 1995; 15:2301-2311.

35 Lee Y, Lopez DE, Meloni EG, Davis M: A primary acoustic startle pathway: Obligatory role of cochlear root neurons and the nucleus reticularis pontis caudalis. J Neurosci 1996;16:3777_ 3789.

36 Hitchcock JM, Davis M: The efferent pathway of the amygdala involved in conditioned fear as measured with the fear potentiated startle paradigm. Behav Neurosci 1991;105:826-842.

37 Rosen JB, Davis M: Enhancement of acoustic startle by electrical stimulation of the amygdala. Behav Neurosci 1988;102:195-202.

38 Tampke AK, Irwin HJ: Dissociative processes and symptoms of posttraumatic stress in Vietnam veterans. J Trauma Stress 1999;12:725738.

39 Globisch J, Hamm AO, Esteves F, Öhman A: Fear appears fast: Temporal course of startle reflex potentiation in animal fearful subjects. Psychophysiology 1999;36:66-75.

40 Resnick HS, Kilpatrick DG, Best CL, Kramer TL: Vulnerability - Stress factors in development of posttraumatic stress disorder. J Nerv Ment Dis 1992;180:424-430. 